\title{
LA INDUSTRIA DEL PISCO ANÁLISIS ECONÓMICO A TRAVÉS DE LA TEORÍA DE JUEGOS
}

\author{
Sonia Tello Rozas \\ Escuela Profesional de Turismo y \\ Hotelería - USMP - Lima
}

\section{INTRODUCCIÓN}

En este artículo analizamos la industria del pisco (aguardiente de vino, bebida nacional del Perú), utilizando las herramientas de la teoría económica. Considerando los numerosos desafíos que esta industria enfrenta y los variados temas que sobre ella se pueden desarrollar, dirigimos nuestra atención hacia la comercialización internacional del producto.

Al explorar la dinámica de la industria, constatamos que la especificidad del producto permite que él sea legal y comercialmente protegido a través de una denominación de origen. Advertimos, además, la factibilidad de aumentar su producción y la existencia de un mercado internacional ¿Por qué razones, entonces, los agentes que participan en la industria no ha logrado posicionar el producto en el mercado internacional?

En el intento de acercarnos a algunas respuestas, estudiamos las interrelaciones entre los agentes que hacen parte de la industria del pisco. Del análisis de las interacciones entre los actores privados, resaltamos la presencia de una gran cantidad de agentes y la ausencia redes y estrategias colectivas. Constatación que coincide con el discurso de los representantes de la industria, el cual hace alusión a la falta de una cultura asociativa (Portocarrero, 2006)
Con respecto a los aspectos teóricos y formales del estudio, utilizamos el capital social como marco de análisis. Este enfoque es novedoso si consideramos la literatura que estudia la industria vitivinícola. En ella, la relación entre los agentes es habitualmente estudiada a partir de la teoría de contratos (Gaucher et al., 2002; Soler et al., 1998). Teniendo en cuenta que la coordinación constituye una expresión del.funcionamiento del capital social, formalizamos el caso a través de la teoría de juegos, particularmente de los juegos de coordinación. Este instrumento permite modelar las fallas de coordinación entre los agentes que participan en la comercialización internacional del producto $y$ explorar los efectos de algunas políticas públicas.

El estudio es doblemente innovador. A través de él formalizamos la ambigua noción de capital social. Además, en este trabajo se presenta, por primera vez, un modelo económico que formaliza la dinámica de una industria sobre la cual la retórica es abundante.

La primera sección del articulo es, talvez, la menos novedosa, pero indispensable para comprender la dinámica de la industria. En ella realizamos un detallado análisis de la industria del pisco, el mismo que es presentado en forma de estudio de caso. La sistematización del caso nos ha sido útil para identificar algunas de las deficiencias existentes en la industria. Las informaciones contenidas en esta sección han sido obtenidas a través de fuentes 
secundarias (libros, artículos periodísticos e informes técnicos) y de entrevistas a actores públicos y privados implicados en la industria.

En la segunda sección, presentamos el marco teórico. Éste se articula en torno de una noción y de un instrumento. La noción es la del capital social, ella ha servido de columna vertebral para realizar el análisis teórico. El instrumento, la teoría de juegos, ha sido útil para modelar el caso. Cabe resaltar que presentamos en esta sección una breve explicación sobe la teoría de juegos, orientada al lector que no está familiarizado con el tema.

Posteriormente, en base a los datos recogidos y al marco de análisis, formalizamos el problema de investigación a través de un modelo. Finalmente, estudiamos el resultado de la aplicación de algunas políticas públicas orientadas a incentivar la inversión dirigida a posicionar el producto, pero, sobretodo, a crear mecanismos que estimulen la coordinación entre los actores privados.

\section{El caso de la industria del pisco}

La producción de las bebidas espiritosas, las cuales se obtienen por destilación y contienen un alto grado de alcohol, tiene una larga tradición en la historia de la humanidad (Dias Blue, 2004; Lichine, 1998). Por el proceso utilizado para su obtención, ellas son clasificadas como aguardientes. Cuando el aguardiente es elaborado a partir de uvas, el producto se conoce como brandy y admite dos tipos: los "finos" y los "marcs" (Lichine, 1998). Los primeros provienen de la destilación del vino, mientras que los marcs son elaborados a partir del orujo de la uva'.

Entre los aguardientes producidos en América, se encuentra el pisco, producto elaborado en el Perú que es obtenido a través de la destilación de mostos fermentados o en proceso de fermentación. Ocho tipos de uva, cultivados en una de las cinco regiones que especifica la legislación peruana ${ }^{2}$, determinan la denominación de origen del producto.

La tradición del pisco en el Perú no es reciente. Es en el siglo XVI, con la llegada de los europeos, que la elaboración de productos vitivinícolas se inicia en esta región sudamericana. Según las crónicas de la época ${ }^{3}$, dos razones motivaron que los conquistadores españoles desarrollasen la actividad vinícola en sus colonias: por un lado, el hábito de consumo de uvas y de sus derivados, por otro, la importancia del vino en los ritos de la iglesia católica. Durante esta época, son los miembros de la Compañía de Jesús que controlan la producción agrícola, concentrando la propiedad de grandes extensiones de terrenos rurales.

Con el transcurso del tiempo, a causa del clima, del sol y de las condiciones geográficas, la producción de uvas aumenta y se concentra al sur de la ciudad de Lima, particularmente entre las regiones de Ica y Moquegua. El aumento de los viñedos permite que se incremente también la fabricación y comercialización de los derivados de la uva, principalmente del vino y del aguardiente. Gracias al creciente consumo de estos productos, Pisco y de Nazca se convierten en dos de los puertos más importantes de la América española (Del Busto et al. 1990), a partir de éstos, el virreinato de Perú exporta sus productos vitivinícolas hacia otras regiones del reino. De esta manera, la primera mitad del siglo XVIII se distingue por la presencia de una industria vitivinícola próspera, con productos muy bien apreciados.

La situación comienza a cambiar en 1767, cuando la Compañía de Jesús es expulsada de España y de sus colonias. A partir de entonces, en Perú, una instancia local representante de la Corona administra los terrenos agrícolas. Los años que siguen son marcados por la pérdida de poder económico del virreinato del Perú. En lo que respecta a la industria del vino y del pisco, a lo largo del siglo XIX, el sector vitivinícola peruano atraviesa una severa crisis, debida principalmente a la mala administración de los

\footnotetext{
'Los aguardientes de vino mejor posicionados en los mercados internacionales son el coñac y el armañac, ambos franceses. Dentro de los marcs (nombre que se utiliza para designar a los aguardientes de orujo en el mercado intemacional), la grapa, aguardiente italiano, es el más popular.

${ }^{2}$ Las cepas autorizadas en la producción del pisco son: Albilla, Italia, Moscatel, Torontel, Mollar, Negra Criolla, Qucbranta y Uvina. En relación con las zonas de producción, cinco son las regiones especificadas en la legislación: Lima, Ica, Moquegua, Arequipa y Tacna. Todas éstas ubicadas al sur oeste del pais.

${ }^{3}$ Bernabé Cobo, Historia del Nuevo Mundo [1653], Biblioteca de Autores Españoles, tomo I, Madrid, 1964; Inca Garcilaso de la Vega, Comentarios Reales [1617], Biblioteca Ayacucho, tomo II, libro 9, Caracas, 1979; Pedro Cieza de León, Crónica del Perí [1551], Biblioteca de Autores Españoles, cap. LXXI, Madrid, 1853.
} 
terrenos rurales y a la presencia de la epidemia de la filoxera ${ }^{4}$. Para la industria vitivinícola peruana esta enfermedad de la uva es decisiva, con ella se pierde una gran parte de las viñas $y$, consecuentemente, la producción de uvas y sus derivados disminuyen drásticamente. La crisis vinícola se agrava aún más con la guerra del Pacífico (Perú Chile, 1879 1883), durante la cual muchas viñas son destruidas.

En el siglo XX, dos etapas caracterizan la industria del vino y del pisco. Durante la primera, se observa una disminución sustancial en la producción vitivinícola debida esencialmente a las condiciones del mercado. Efectivamente, en esta época, el cultivo de vides es substituido por el de productos con una creciente demanda en el mercado local (caña de azúcar, alfalfa) e internacional (algodón, arroz). La segunda etapa, que se inicia a fines de los años de 1980, se distingue por el esfuerzo realizado por entes públicos y privados con el fin de hacer reconocer el pisco como un producto único y de incrementar su demanda nacional e internacional. Durante este período, el gobierno, buscando satisfacer las demandas de empresas productoras de pisco, toma medidas para proteger el producto y facilitar su comercialización. Así, en 1989 son determinadas las normas técnicas para la producción del pisco. Éstas establecen la definición del producto, su clasificación, las condiciones generales para su elaboración así como las propiedades requeridas para que el producto reciba la denominación de origen: pisco $^{5}$.

Es oportuno señalar que, en el mercado internacional, existe otra bebida alcohólica que es admitida como pisco. Desde 1985, Chile reconoce y comercializa el aguardiente de vino producido en dos regiones específicas de su territorio con el nombre de pis $\mathrm{CO}^{6}$. Con el objetivo de proteger las particularidades del producto peruano y de facilitar su comercialización en los mercados internacionales, el estado peruano solicitó la inscripción del producto en el Arreglo de Lisboa para la Protección de Denominaciones de Origen y su Registro Internacional. Dicho Arreglo reúne una veintena de países comprometidos en la protección y el registro internacional de las denominaciones de origen de una serie de productos. La solicitud peruana con relación al pisco fue aceptada, en 2005, por 21 de los 24 países miembros.

Teniendo en cuenta la importancia del mercado vitivinícola mundial en la actualidad, consideramos que los retos que la industria del pisco debe afrontar son numerosos. Si bien el pisco es un producto con perspectivas de crecimiento tanto en su oferta como en su demanda, muchas son las dificultades a ser superadas: la industria integra un gran número de pequeños productores y de productos heterogéneos, ella enfrenta una baja productividad y la ausencia de estrategias de marketing eficaces. Pero sobre todo, la industria del pisco presenta problemas de coordinación entre los actores que en ella participan. En los párrafos que siguen, exponemos algunos elementos que facilitan el análisis de la industria y la formalización, a través de un modelo teórico, de las fallas de coordinación. Primeramente analizamos el mercado del aguardiente de vino peruano, tanto del lado de la oferta como de la demanda. En seguida, examinamos los aspectos relativos a la organización de la industria. Finalmente, intentamos establecer un vínculo entre la situación de la industria de pisco y un marco teórico pertinente.

\subsection{El mercado}

Con el fin de analizar el mercado del pisco, examinamos, en primer lugar, la situación de la demanda mundial; en seguida, centramos nuestra atención en la demanda nacional, y finalmente analizamos la producción.

Nos parece oportuno recalcar que el pisco hace parte del mercado de las bebidas espiritosas. Según los datos publicados por Vitisphere S.A.(2005), el consumo mundial de este tipo de bebidas alcohólicas fue de 2,7 mil millones de cajas de 9 litros en el año de 2003, mostrando una evolución positiva de $6,3 \%$ desde 1999. De acuerdo a las previsiones, la demanda de las bebidas espiritosas

${ }^{4}$ La filoxera es una enfermedad de la vid proveniente de los Estados Unidos que atacó y devastó los cultivos de uva de numerosos paises al final del siglo XIX. Chile fue una de las únicas regiones que no fue afectada. Sus vides se utilizaron para la reconstrucción de viñedos de otros paises

${ }^{5}$ En 2002, la norma técnica es ratificada por el Instituto Nacional de Defensa de Competencia y la Protección de la Propiedad Intelectual (INDECOPI).

${ }^{6}$ Ver el Decreto número 521 del Departamento de viñas y vinos de la división de protección agricola Gobierno de Chile, Diario Oficial de la República de Chile, 27 de mayo de 2000 (disponible en Internet, en el sitio:http://www.Sag.Gob.Cl/pls/portal/docs/PAGE/PG_SAG_BIBLIOTECA/BIBL_INSYPROD/BIBLIO_INS_VINOS/BIBLIO_ INS_VINOS_NORMAS/DECRETO_521_0.PDF). 
exhibirá una progresión de $12,3 \%$ en período comprendido entre 2003 y 2008.

Examinando la distribución de la demanda, notamos que Asia constituye el mercado más importante para estas bebidas. En 2003, los consumidores asiáticos compraron $55,5 \%$ de la producción mundial, es decir 1,5 mil millones de cajas de 9 litros. El incremento no es exclusivo al continente asiático, él se observa también en Europa y América del Norte. En el caso de América Latina, entre 1999 y 2003, el consumo disminuyó en $4,3 \%$. Sin embargo, se predice un aumento en el consumo de $6,7 \%$ hasta el año 2008.

Con relación al pisco, el producto está en competencia con dos bebidas muy bien posicionadas en los mercados internacionales. Los substitutos más próximos y más conocidos mundialmente son los aguardientes de vino franceses con denominación de origen controlada: el coñac y el armañac. Existe un tercer substituto del pisco, se trata del aguardiente de vino de Chile, bebida fabricada principalmente con la variedad de uva moscatel.

En general, comparando el volumen de exportación del pisco con el de los aguardientes que provienen de otros países, notamos que la venta del pisco en los mercados internacionales es aún marginal. Como se evidencia en el cuadro 1.1, el volumen mundial exportado de aguardientes y productos similares, para el año 2004, es de 2,631, 871 miles de dólares americanos, mientras que, según la Comisión para la Promoción de las Exportaciones (PROMPEX), el Perú exporta solamente 483,000 \$US, siendo los Estados Unidos el mercado más importante (cuadro 1.2).

Cuadro 1.1 - Exportaciones mundiales de aguardiente, 2004

\begin{tabular}{|l|c|c|}
\hline \multicolumn{1}{|c|}{ País } & Miles \$US & $\%$ \\
\hline Francia & 1714963 & 65,0 \\
\hline Singapur & 234153 & 8,9 \\
\hline España & 158576 & 6,0 \\
\hline Hong Kong & 115056 & 4,4 \\
\hline Italia & 87017 & 3,3 \\
\hline Alemania & 53538 & 2,0 \\
\hline Alemania & 38373 & 1,5 \\
\hline Malasia & 27316 & 1,0 \\
\hline Otros & 200650 & 79,2 \\
\hline Total mundo & 2637871 & 100 \\
\hline
\end{tabular}

Fuente: Comisión para la Promoción de las Exportaciones en el Perú (PROMPEX)

Cuadro 1.2 - Exportaciones peruana de Pisco, 2005

\begin{tabular}{|l|c|c|}
\hline \multicolumn{1}{|c}{ País } & Miles \$US & \% sobre total exportado \\
\hline Estados Unidos & 257.405 .05 & 53,29 \\
Reino Unido & 80.121 .46 & 16,59 \\
España & 9.783 .17 & 8,95 \\
Chile & 7.050 .00 & 2,95 \\
Japón & 4.435 .81 & 2,68 \\
Otros & 75.036 .22 & 15,54 \\
\hline Total & 482.983 .62 & 100 \\
\hline
\end{tabular}


Sobre la demanda local (peruana) de bebidas alcohólicas, ella exhibe una evolución positiva en los últimos años y se caracteriza por estar muy concentrada en el mercado de la capital: $80 \%$ de las bebidas alcohólicas industrializadas son consumidas en Lima, siendo la cerveza y el ron los productos más vendidos (cuadro 1.3).

Cuadro 1.3 - Consumo de bebidas alcohólicas en Perú, 2004 y 2005 (en millones de litros)

\begin{tabular}{|lccl|}
\hline \multicolumn{1}{|c}{ Bebida } & 2004 & 2005 & Variación \\
\hline Cerveza & 67,3 & 797 & $18,42 \%$ \\
Ron & 10,5 & 10.7 & $1,90 \%$ \\
Vinos y espumantes & 4,8 & 5.8 & $20,83 \%$ \\
Pisco & 0,6 & 0.8 & $33,33 \%$ \\
\hline
\end{tabular}

Fuente: Les boissons alcoolisées au Pérou, Fiche de synthèse, Missions économiques, abril 2006.

Con respecto al otro componente del mercado, la producción y la oferta de vitivinícola, subrayamos que el cultivo de vides se concentra en el sur del Perú. En este espacio geográfico había, entre 2001 y 2002, alrededor de 11000 hectáreas disponibles para la actividad vitícola, en él se producía un total de 127, 804 toneladas de uva. Una comparación del espacio ocupado por las viñas en Perú y el utilizado con el mismo fin en otros países de América, muestra que la superficie de los viñedos peruanos representaba, en esa época, sólo un 1,16 $\%$ del total cultivado en el continente (cuadro 1.4).

Cuadro 1.4 - Superficie de Viñedos en América, 2001 - 2002

(en miles de hectáreas)

\begin{tabular}{|lccc|}
\hline \multicolumn{1}{|c}{ América } & 2001 & 2002 & $\begin{array}{c}\text { Variación } \\
(\%)\end{array}$ \\
\hline Canadá & 9 & 9 & 1,35 \\
Estados Unidos & 426 & 415 & 2,45 \\
México & 40 & 41 & 1,19 \\
Argentina & 205 & 208 & 1,19 \\
Bolivia & 4 & 5 & 16,45 \\
Brasil & 63 & 65 & 3,1 \\
Chile & 181 & 184 & 1,66 \\
Perú & 12 & 11 & 5,54 \\
Uruguay & 10 & 10 & 0,84 \\
Venezuela & 1 & 1 & 1,17 \\
Otros países de América & 2 & 2 & 0,24 \\
\hline Total América & 952 & 950 & 0,18 \\
\hline
\end{tabular}

Fuente : Organización Internacional de la viña y el vino (O.I.V.). 
Sin embargo, como ilustra la figura 1.1, la producción de uvas en Perú exhibe, desde 1990, un crecimiento promedio de $20 \%$ : ésta ha pasado de 55,500 toneladas en 1990 a 127,800 toneladas en 2001.

Figura 1.1 - Producción de uvas en Perú, 1995-2001

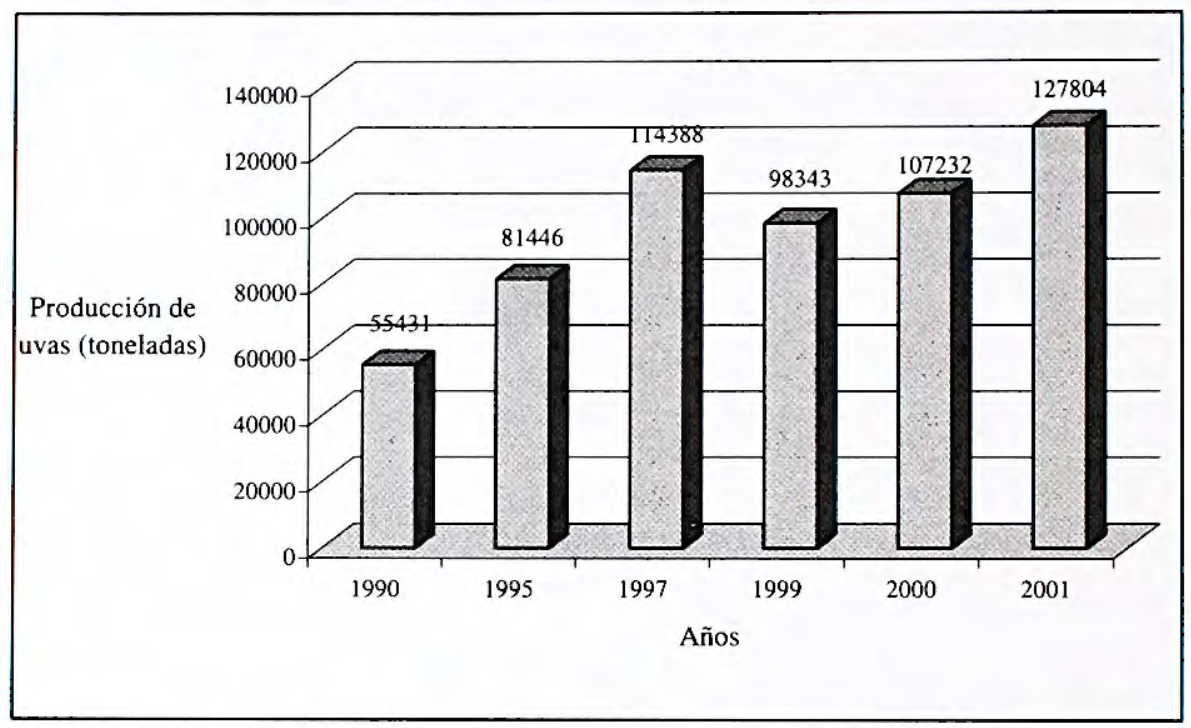

Fuente: Centro de Innovación Tecnológica Vitivinícola - Ministerio de la Producción del Perú.

Realizando un análisis de la distribución de la superficie agraria destinada a los distintos productos de la industria vitivinícola (cuadro 1.5), observamos que $69 \%$ de los terrenos $(7,947 \mathrm{ha}$ ) es empleado en la producción de uvas para el consumo directo; $21 \%$ ( 2,431 ha) es utilizado en el cultivo de cepas orientadas a la fabricación de vino y $10 \%(1,200 \mathrm{ha})$ se dedica a la fabricación de pisco.

Paralelamente al incremento en el cultivo de uvas para el consumo directo y para la producción del vino, las viñas destinadas a la producción de uvas pisqueras aumentaron a partir de la década de 1990. En consecuencia, la producción de aguardiente de uva presenta una variación positiva: de 2002 a 2003, la producción se incrementó en 55 $\%^{7}$; en al año 2005, la elaboración del pisco fue de 3,94 millones de litros, cifra que se traduce en un crecimiento de $36 \%$ en relación al año precedente ${ }^{8}$. Debemos subrayar, a pesar de ello, que la producción de esta bebida se encuentra aun por debajo de su capacidad potencial. En ese sentido, tomando en cuenta la capacidad de las instalaciones, el Ministerio de la Producción del Perú calcula que la fabricación potencial de pisco es de 4705,000 litros, pero que el volumen de producción real es solamente de 1500,000 litros. El cuadro 1.5 resume estas informaciones.

\footnotetext{
" "Gobiemo buscará que origen del pisco sea reconocido por OMC", Diario el Comercio de Lima, 28 julio de 2005).

"Julio Escalante, "Este fin de semana nuestro país celebrará el Día del Pisco Sour" Diario el Comercio de Lima, 1 febrero de 2005.
} 
Cuadro 1.5 - Producción de uvas y de pisco, 2001

\begin{tabular}{|l|l|}
\hline Superficie cultivada de uva (Lima, Arequipa, Moquegua y Tacna) & 11558 ha \\
\hline Superficie cultivada para & \\
\hline consumo directo & 7947 ha( $68,6 \%)$ \\
\hline Producción de vino & 2431 ha $(21,0 \%)$ \\
\hline Producción de pisco & 1200 ha $(10,4 \%)$ \\
\hline Distribución de la superficie agraria destinada a cepas pisqueras: & \\
\hline Ica & 768 ha $(64 \%)$ \\
\hline Lima & 300 ha $(25 \%)$ \\
\hline Arequipa, Moquegua, Tacna & 132 ha (11\%) \\
\hline Total & 1,200 ha (100\%) \\
\hline Volúmen de productos de pisco & \\
\hline
\end{tabular}

Fuente: Centro de Innovación Tecnológica Vitivinícola - Ministerio de la Producción del Perú (cifras aproximadas).

Numerosos son los agentes que participan en la producción, comercialización y distribución de pisco. Con el fin de delinear la cadena de producción, en los parágrafos que siguen describimos las etapas y los agentes implicados en cada fase del proceso productivo.

\subsection{La dinámica de la industria del pisco y los agentes implicados}

En la cadena de producción del pisco se distinguen tres fases: 1) la producción de las uvas; 2) la transformación de las uvas (vinificación y destilación); 3) la distribución y comercialización. Con el objetivo de analizar las relaciones y la dinámica existente entre los agentes que participan en esta cadena productiva, a continuación examinamos cada una de estas etapas. Para ilustrar la dinámica de la industria, utilizamos los datos correspondientes al año 2001.

\subsubsection{Producción de uvas}

Para estudiar la producción de las uvas pisqueras, tres aspectos deben ser considerados. El primero concierne a la superficie agrícola. Recordemos que la superficie utilizada para el cultivo de cepas orientadas a producir pisco era, en 2001, de 1,200 ha, espacio equivalente al $10 \%$ de las hectáreas disponibles para el cultivo de uva en el Perú. En esta extensión agraria se producían 12,780 toneladas de uvas pisqueras. Al realizar una comparación entre esta extensión y la que es utilizada con la misma finalidad en Chile, notamos que la producción de cepas en Perú es sensiblemente inferior. Efectivamente, según el Servicio Agrícola, en Chile había, en el año 2001, 9,700 ha, de terrenos destinados a la producción de cepas utilizadas para la elaboración del aguardiente de uva.

El segundo aspecto a resaltar está relacionado con las actividades que se llevan a cabo durante la producción de uvas. Dos entre ellas son las principales: el cultivo de las cepas y la cosecha de las uvas destinadas a la fermentación (la vendimia) ${ }^{9}$. Con respecto al cultivo, él representa un costo importante dentro de la producción de las uvas; de acuerdo al Centro de Innovación Tecnológica Vitivinícola del Ministerio de la Producción (Rosadio et al., s.f entre 2000 y 2005), el costo promedio de una nueva hectárea de viñas asciende a $12,000 \$ \cup S^{10}$. Teniendo en cuenta que esta fase de la cadena productiva se caracteriza por

'Entre estas dos actividades hay una serie de tareas indispensables para la producción de uvas tales como el control de la humedad, la irrigación de los terrenos, el control del crecimiento de los pies de las viñas, entre otros.

${ }^{10} \mathrm{~F}$. 2000 et 2005), esto significa que una hectárea cultivada de uvas sirve para producir 1800 botellas de $750 \mathrm{cc}$ de pisco aproximadamente. 
la presencia de un gran número de pequeños productores, ampliar la superficie de viñedos constituye un freno para el incremento de la producción del pisco. En lo que se refiere a la vendimia, ella se realiza durante los meses de febrero y marzo, periodo en el cual la cosecha de uvas es conducida a las bodegas para su transformación en pisco.

El papel de los actores implicados en la producción de uvas, tanto de los que hacen parte del sector privado, representados por los productores, como de aquellos del sector público, es el tercer aspecto importante a ser analizado. Dentro del sector privado, observamos la participación de una gran cantidad de productores. En el año 2001, se identificaron 921 productores de cepas pisqueras, los cuales conforman tres grupos: el primero y más numeroso está constituido por 900 propietarios de pequeñas explotaciones agrarias cuyas extensiones alcanzan hasta 1,5 ha; el segundo, es conformado por 15 dueños de terrenos de mediana extensión y el tercero compuesto de 6 grandes viñedos. La gran mayoría de los productores que poseen viñedos de reducida extensión, venden la totalidad de su producción a fabricantes de pisco. En este grupo, el nivel de tecnificación es escaso y está acompañado de bajos niveles de productividad. Además, estos pequeños productores tienen restricciones de acceso a los mercados de crédito y demuestran una limitada capacidad asociativa. Cabe resaltar a ese respecto que son raros los casos en los que pequeños productores se organizan en cooperativas o en agrupaciones de productores con el objeto de aumentar su poder de negociación. En relación con los otros dos grupos, los propietarios de medianas y grandes explotaciones, ellos producen tanto sus cepas como el aguardiente.

Finalmente, notamos que el sector público participa en esta fase de la cadena productiva a través de dos ministerios, el Ministerio de Agricultura y el de la Producción. El primero es responsable del control y la promoción de la actividad agrícola, el otro ofrece servicio de ayuda tecnológica.

\subsubsection{La cosecha y transformación de las uvas: la producción de pisco}

Una vez que las uvas son cosechadas, su transformación en pisco se realiza en las bodegas. En efecto, las uvas cosechadas son transportadas a las bodegas para seguir un proceso de prensado. El mosto así obtenido es fermentado (proceso de vinificación) y posteriormente destilado. Después de un período de reposo, el pisco, producto de la destilación, es embotellado y etiquetado.

Entre los actores que participan en la transformación de las uvas en pisco, encontramos dos tipos de productores: los productores agroindustriales y los "piqueros". Los primeros son propietarios de viñas como también de bodegas y de equipos necesarios para la fabricación del producto. Los segundos poseen bodegas pero no poseen viñedos, ellos siven de intermediarios para la fermentación y destilación del producto.

En este proceso de industrialización, 180 bodegas transforman las uvas en mosto y luego en pisco. Entre ellas, identificamos 161 bodegas artesanales (que fabrican el $43 \%$ de la producción de pisco), 10 bodegas de talla mediana (20\%) y 9 grandes bodegas ( $37 \%$ ). Como en la fase de producción de la uva, observamos que la elaboración del pisco es también una actividad muy segmentada. En ella notamos la ausencia de cooperativas o de consorcios de producción, hecho que dificulta el establecimiento de estrategias orientadas a mejorar la productividad y la comercialización del producto.

Además de los productores, otros actores, públicos $y$ privados, participan en el proceso de industrialización. Se trata de organizaciones, en lugar de agentes individuales, que juegan un rol importante en el funcionamiento de la industria. Es el caso del Consejo Nacional de Ciencia y Tecnología (CONCYTEC), organismo responsable de controlar el cumplimiento de las normas técnicas establecidas para la obtención de la denominación de origen, y del Ministerio de la Producción que, a través del Centro de Innovación Tecnológica Vitivinícola (CITEvid), ofrece servicios de consultoría orientados al mejoramiento tecnológico de la producción. Dentro del grupo de 
las organizaciones privadas, existen dos tipos de asociaciones: una representa a los grandes productores de pisco y a los productores que, por poseer marcas posicionadas en el mercado local, tienen cierto poder de lobby frente al gobierno (el Comité Vitivinícola de la Sociedad Nacional de Industrias); el otro agrupa a los pequeños productores de las cinco regiones que cuentan con la denominación de origen (Asociación Nacional de Productores de la Viña y del Pisco, Perú Pisco)". Finalmente, constatamos la presencia de un nuevo organismo privado encargado, desde el año 2006, de controlar la calidad del producto de sus asociados, es el Consejo Regulador de la Denominación de Origen Pisco.

\subsubsection{La comercialización y la distribución}

Existen tres niveles de comercialización del producto en el mercado: los niveles local, nacional e internacional. La comercialización local es el mecanismo más popular entre los pequeños productores, ella se realiza de manera directa, entre el productor y el consumidor. En este nivel, se nota un escaso grado de coordinación entre los agentes, el mismo que no les permite conciliar estrategias de comercialización eficaces ni ampliar sus mercados. Adicionalmente, observamos que el producto sólo esta disponible en la localidad y su calidad no es controlada. Finalmente, la diversificación de bebidas fabricadas a base de pisco está ausente y no existen espacios comunes de comercialización, como una tienda de pisco en cada localidad, por ejemplo.

Si observamos a una escala más amplia, el mercado nacional, constatamos que el consumo $y$, consecuentemente, la comercialización, son altamente concentrados en la capital. En el mercado limeño, las empresas venden el producto a supermercados (sus consumidores más importantes), mayoristas, cafés, bares, restaurantes, hoteles y embajadas. En él, a pesar de la presencia de numerosas marcas de pisco, las marcas más conocidas están bien posicionadas.

A nivel de los mercados internacionales, nos parece necesario precisar algunos aspectos relacionados con las estrategias de comercialización; con tal fin, tomamos como referencia el caso del vino. Como explican Gaucher et al. (2002), en la industria vinícola existen dos formas de organización. La primera, común entre los países europeos, se basa en las denominaciones de origen. En este modelo, los productores realizan sus esfuerzos de comercialización y de promoción a través de organizaciones colectivas. La segunda forma de organización, observada especialmente entre los "nuevos" países productores, como Australia, Nueva Zelanda y Estados Unidos por ejemplo, se basa en las cepas y las marcas. Los costos de promoción son, en este caso, asumidos directamente por las empresas individuales. En la industria del pisco, los actores que en ella participan han privilegiado la estrategia de denominación de origen con el fin de proteger el producto de la competencia internacional; pero, paralelamente, ellos han escogido la estrategia de marcas para su comercialización.

El carácter único del producto justifica la elección de la estrategia de denominación de origen. Sin embargo, esta estrategia es desventajosa cuando no existe una sólida organización empresarial. En el caso peruano, las organizaciones colectivas que agrupan a productores individuales no son sólidas ni se orientan a desarrollar estrategias de promoción. Adicionalmente, las empresas que tienen capacidad de exportar son competidoras en el mercado nacional y tienen que asumir los costos de promoción, tanto nacional como internacional, de manera individual. Estos costos, sobretodo los relativos a la promoción internacional, tienen un peso relativo muy importante sobre los costos totales $^{12}$. Los altos costos que implica la comercialización internacional y el posicionamiento del producto junto con la

\footnotetext{
"Del total de pequeños productores de uva y de pisco, un tercio hacen parte de Perú Pisco.

${ }^{12}$ En el caso de Chile, mercado en el cual las empresas Capel y Compañia Pisquera de Chile mantienen el oligopolio de la industria de aguardiente de vino, Roberto Salinas, director general de Capel, afirma que la empresa invirtió 5 millones de dólares americanos a fin de entrar en le mercado americano sin tener resultados significativos. Según el director general de la firma concurrente, Alvaro Femández, es necesario invertir, en marketing y promoción, durante 5 años para tener resultados positivos en el mercado internacional de los aguardientes (Russell, E. , 2006)
} 
elevada probabilidad de free riding "' (disfrute libre"), tienen un efecto negativo sobre el esfuerzo de inversión en marketing y promoción de los empresarios que participan en la industria. En consecuencia, la comercialización del pisco en mercados extranjeros es marginal: según los datos disponibles, de los 1500000 litros de pisco producidos en 2001, solamente $6 \%$ era exportado.

No solamente este porcentaje de exportación es reducido, además éste es repartido entre numerosos productores. Según la Comisión para la Promoción de las Exportaciones en Perú (PROMPEX), en el año 2001, 25 empresas peruanas exportaban pisco, concentrando las 10 primeras el $98,5 \%$ de las ventas.

La comercialización en el extranjero se realiza a través de los importadores y de los distribuidores. En ambos casos, cada productor de pisco contacta individualmente a sus clientes y negocia con ellos las condiciones de venta. La promoción, cuando ella es realizada por el distribuidor, tiene el fin de vender una cantidad determinada de pisco. La apertura de nuevos mercados y el posicionamiento del producto dependen entonces del esfuerzo de inversión del productor.

Con relación a la comercialización del pisco en los mercados internacionales, es importante hacer notar que existe una voluntad política orientada a aumentar las exportaciones del producto: el pisco es reconocido como "producto bandera" y recibe, junto con otros productos $y$ servicios, un presupuesto destinada a la comercialización, exportación y protección. Dos organismos del Estado (Promperú PROMPEX y el Ministerio de Relaciones Exteriores) son los encargados de la promoción del pisco en el exterior. El esfuerzo para que el pisco entre en nuevos mercados es evidente; pero la coordinación entre las entidades y los agentes implicados en la industria es deficiente.

La figura 1.2 resume las informaciones referentes a la dinámica del sector y a las relaciones entre los
En resumen, del análisis de la dinámica de la industria del pisco, podemos resaltar los siguientes elementos:

El contexto. En el caso de la industria peruana del pisco, se observa la ausencia de una historia de interrelaciones entre los actores que en ella participan. En tal sentido, la producción del pisco es una actividad que se realiza de manera individual: los empresarios que hacen parte de la industria no tienen experiencia en la definición de estrategias conjuntas, asimismo, ellos tienen dificultades en asociarse para alcanzar objetivos específicos. Además, existe un gran prejuicio hacia las cooperativas y no existen consorcios de producción.

La protección jurídica. El pisco es un producto que cuenta con una denominación de origen controlada, motivo por el cual sólo puede ser elaborado en una región. Para conservar esta protección jurídica, los productores deben respetar ciertos procesos en la elaboración del producto. Es por ello que el costo del pisco es más alto comparativamente con otros aguardientes que no cuentan con la denominación.

Los productores. El sector está caracterizado por la presencia de un gran numero de productores artesanales, que orientan sus actividades hacia los mercados locales, y un pequeño grupo de medianos y grandes productores que tienen la capacidad de exportar el producto de manera esporádica, pero no que no pueden asumir, de manera individual, los costos de posicionamiento internacional del producto.

El mercado. Existe un mercado potencial para el producto.

Los costos asociados al comercio internacional del pisco. La especificidad del producto hace que el costo de posicionamiento de producto en mercados internacionales sea alto. Sin embargo, este costo es decreciente en el tiempo: una vez que el mercado esta abierto y que el producto es conocido, las empresas pueden exportar con mucha más facilidad. Asimismo, el desarrollo de

"El problema del free riding se produce cuando un agente quiere obtener gratuitamente (o realizando el mínimo esfuerzo posible) un bien, un servicio o un beneficio mientras que otro paga (o realiza un esfuerzo mayor) por ello. El problema es comúnmente observado en el caso de los bienes públicos. 
Figura1.2 - Cadena de producción del pisco, datos 2001

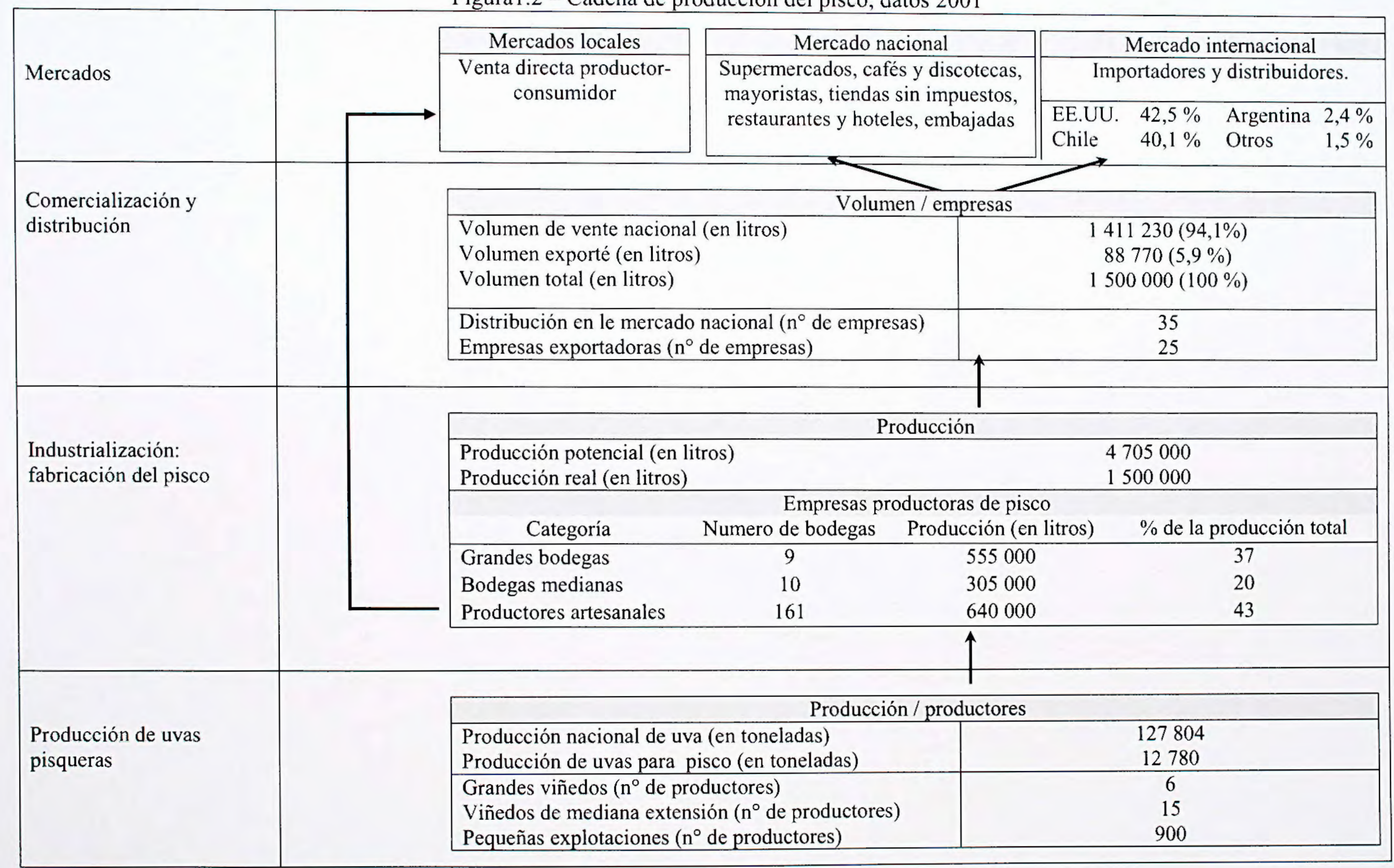

Fuente : CITEvid, Minsiterio de la Producción, Perú. 
nuevos mercados depende del esfuerzo de los agentes privados que toman la decisión de inversión. Teniendo en cuenta la alta probabilidad de free riding, los incentivos que recibe un productor para invertir antes que los otros son reducidos: ninguna empresa invertirá en el posicionamiento del producto si no esta segura que las otras realizarán el mismo esfuerzo de inversión.

De los numerosos desafíos que enfrenta la industria del pisco, nosotros decidimos profundizar en el análisis de su comercialización internacional. Teniendo en cuenta que las posibilidades de exportar el pisco son considerables, ¿por qué motivos los actores que participan en la industria no aumentan sus esfuerzos de inversión, particularmente los orientados a posicionar el producto en mercados internacionales? Con el fin de acercarnos a algunas respuestas, en las secciones siguientes formalizamos el caso del pisco. Para tal fin, tomamos en cuenta que la débil performance del proceso de comercialización internacional es debida, en gran medida, a la ausencia de redes y la carencia de coordinación entre los actores que participan en la industria.

\section{EL MARCO TEÓRICO}

Teniendo en cuenta que existen deficiencias de coordinación entre los agentes que hacen parte de la industria del pisco, proponemos estudiar la comercialización internacional del producto a partir de dos nociones. La primera, que sirve de eje central a nuestro marco teórico, es la de capital social. La otra, la noción de juegos de coordinación (Cooper, 1999; Cooper et al., 1990; Schelling, 1986; Van Huyck et al., 1990), constituye un instrumento particularmente interesante para modelar la interacción entre los agente económicos.

\subsection{El capital social}

La noción de capital social ha sido tratada en la literatura a partir de distintas disciplinas (economía, sociología, administración) y con diferentes objetivos. Algunos autores la utilizan para analizar ciertos elementos de la organización social, como las normas, la confianza, las convicciones comunes (Putnam, 1993; Healy et al., 2001). Otros la emplean con el propósito de estudiar las consecuencias de la participación en una red (Bourdieu, 1996; Coleman, 1990).

Nosotros, tomando como referencia los trabajos de Bowles y Gintis (1998, 2000), empleamos la noción para referirnos a la estructura de interacciones sociales (una red) que permite la coordinación entre los agentes económicos ${ }^{14}$. Dos elementos caracterizan esta estructura: 1) los costos de entrada y de salida de la red son elevados; 2) las relaciones entre los miembros no son anónimas. Es por ello que la información compartida y la confianza constituyen elementos claves para su funcionamiento. Consideramos, asimismo, que las interrelaciones entre los agentes son una consecuencia de las "creencias" (beliefs) que cada uno de ellos tiene con respecto a las acciones de los otros miembros de la estructura. Dicho en otras palabras, el capital social constituye la manifestación de las creencias que los agentes construyen a priori acerca de la acción de los otros ( $X$ evalúa sus posibles acciones considerando la posible decisión y acción de Y). En ese sentido, la coordinación es la concretización de cómo funciona el capital social.

Es preciso señalar que el capital social se construye a través de la interacción entre los miembros de un grupo: la historia de las interacciones determina entonces la existencia y el funcionamiento de la estructura.

Con el objeto de formalizar la noción, dirigimos nuestra atención hacia la teoría de juegos. En ese sentido, en los párrafos que siguen hacemos una breve referencia a la teoría de juegos y a los elementos que estructuran los juegos de coordinación.

2.2 La teoría de juegos y los juegos de coordinación

\footnotetext{
${ }^{14}$ Dasgupta (2002) y Woolcock (1998) utilizan una perspectiva similar para trabajar con esta noción. Estos autores estudian el capital social como un sistema de relaciones entre las personas asi como entre grupos de agentes.
} 
La teoría de juegos estudia las interacciones que se producen durante el proceso de toma de decisiones. "Esta teoría considera como un juego cualquier problema de toma de decisiones, donde el rendimiento de una persona depende no sólo de su propia decisión, sino también de las otras personas" (Maddala et al., 1991: 401). Es decir, ella busca explicar cómo debe comportarse un individuo racional, que busca maximizar su bienestar, en una situación en la que sus ganancias dependen de la decisión de otros individuos racionales que persiguen el mismo objetivo.

Para analizar un problema utilizando el enfoque de la teoría de juegos es necesario especificar la descripción del juego. La descripción de la forma estratégica o normal de un juego es definida por cuatro elementos: 1) el conjunto de jugadores; 2 ) el espacio de estrategias; 3 ) la posible selección de estrategias de cada jugador; 4) las ganancias obtenidas por cada jugador a partir de una combinación particular de estrategias. Las interacciones de los agentes pueden ser representadas en forma de una matriz de rendimientos, como la que presentamos en la figura 2.1 por ejemplo:
La solución del juego (anticipar qué decisión tomarán los agentes) es habitualmente expresada a través de un "equilibrio de Nash". Éste es representado por un número determinado de estrategias (generalmente un par) mediante las cuales cada jugador maximiza su ganancia, teniendo en cuenta la decisión de sus contrincantes. En otras palabras, un conjunto de estrategias constituyen un equilibrio de Nash si ningún jugador se beneficia cambiando su estrategia mientras los otros no cambien la suya.

El ejemplo utilizado por Cooper et al. (1990), presentado en al figura 2.1, nos ayudará a precisar algunos conceptos para comprender mejor la lógica utilizada en la teoría de juegos. Se trata de un juego simétrico donde participan dos jugadores (A y B) que tienen a su disposición un espacio de estrategias $\left(s_{,}\right)$que contiene tres estrategias $\left(s_{i} \quad 1,2,3\right)$, donde $s_{i} \quad s_{i}$ (es decir que cada estrategia $s_{i}$ hace parte del espacio $S_{i}$ ). En él, los jugadores (agentes económicos en general) obtienen las ganancias que especificamos en cada una de las celdas de la matriz de rendimientos. La cifra ubicada en la parte superior izquierda de cada celda, corresponde a la ganancia que obtendrá el jugador A. La otra, ubicada en la parte inferior derecha, representa la ganancia de $B$.

Figura 2.1 - Matriz de rendimientos de un juego de coordinación

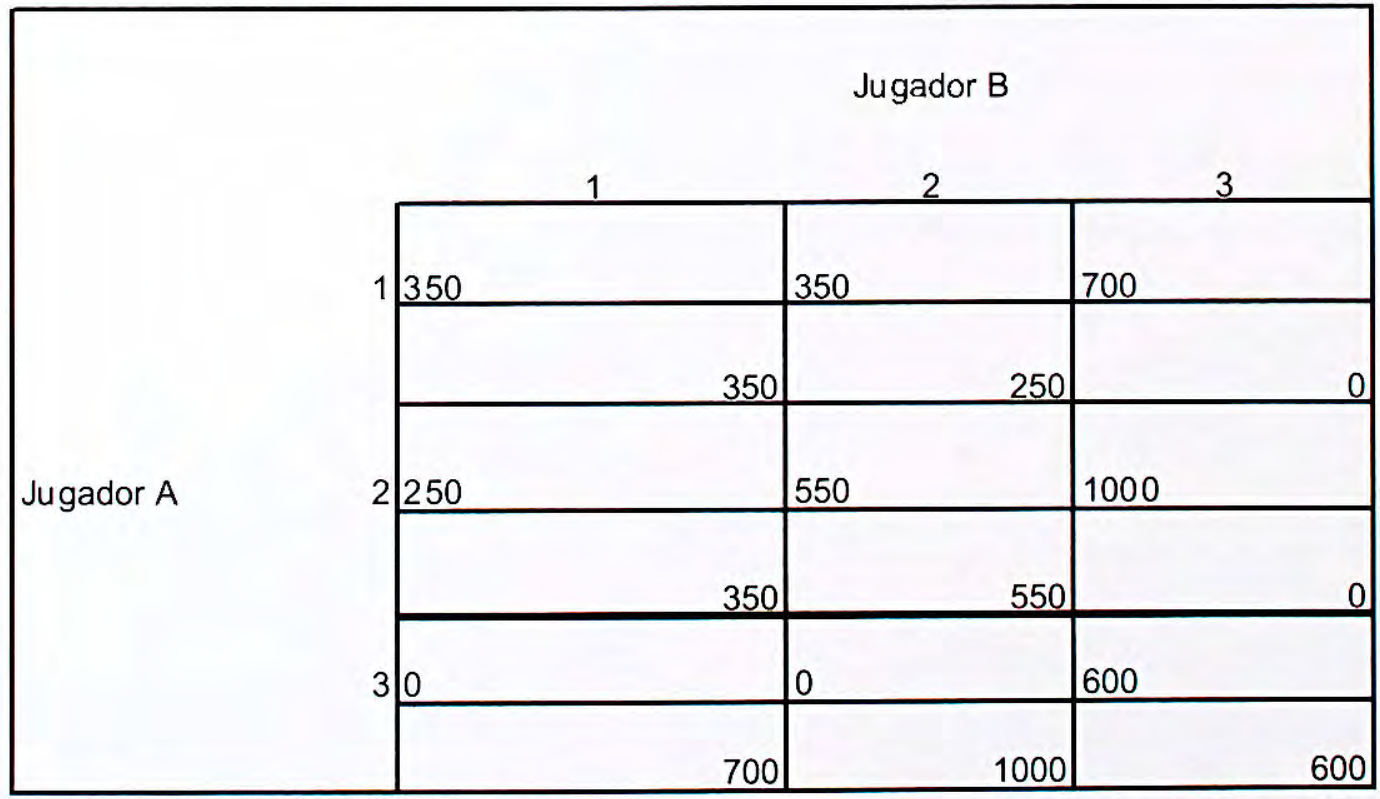

Fuente: Cooper et al. "Selection Criteria in Coordination Games: Some Experimental Results", The American Economic Review, 1990 
Es oportuno recordar que los agentes toman sus decisiones previendo la acción de los otros agentes. En este juego específico, por ejemplo, si el agente $A$ piensa que $B$ escogerá la estrategia 1 , su mejor respuesta será elegir también la estrategia 1 , con ella el agente ganará 350 (cifra mayor a la obtenida con las estrategias 2 y 3 , que son de 250 y 0 respectivamente). Siguiendo la misma lógica podemos determinar los equilibrios de Nash (las estrategias escogidas simultáneamente por los jugadores). En este caso, dos combinaciones posibles corresponden a los equilibrios de Nash en estrategias puras: $(1,1)$ y $(2,2)$; donde la primera combinación genera una ganancia menor que la segunda.

Con respecto a los juegos de coordinación, se trata de juegos en los que los agentes poseen toda la información acerca de las ganancias que se obtienen con cada una de las estrategias escogidas (juegos a información completa). Ellos se caracterizan además porque las ganancias son obtenidas de la confianza y no del conflicto (actuando conjuntamente se consiguen ganancias más elevadas). Los agentes seleccionan sus estrategias de manera independiente y simultánea, es por ello que el juego admite múltiples equilibrios de Nash; estos equilibrios son clasificados de acuerdo a las ganancias que en ellos se puede conseguir. Una falla de coordinación se produce si los agentes escogen un "equilibrio inferior": un equilibrio en el cual las ganancias son menores comparativamente a las de otro equilibrio. Dicho en otras palabras, en este tipo de juegos los agentes pueden aumentar sus ganancias coordinando sus acciones.

Regresando al ejemplo de la figura 2.1, la estrategia 3 es una estrategia dominada'. Sin embargo, en el caso en el que los agentes pueden coordinarse, ella constituye la mejor solución simétrica del juego. Se trata entonces de una estrategia cooperativa y su resultado se conoce comoganancia de cooperación.
Entre los dos equilibrios de Nash, aquel que exhibe una ganancia más elevada, $(2,2)$, constituye un equilibrio "Pareto dominante" $\mathrm{o}$ un equilibrio de Nash dominante por ganancia (Van Huyck et al., 1990). El otro, $(1,1)$, es un equilibrio ineficaz puesto que produce una ganancia menor. La selección del equilibrio ineficaz constituye una falla de coordinación.

\subsubsection{La selección de los equilibrios en los juegos de coordinación}

La predicción del equilibrio que será seleccionado por los agentes constituye una de dificultad frecuente en el análisis de los juegos de coordinación. Es por esta razón que el tema (la selección de los equilibrios) ha sido ampliamente estudiado en la literatura. Camerer (2003), por ejemplo, subraya la existencia de múltiples principios de selección. Según este autor los equilibrios son escogidos por repetición (el agente selecciona el equilibrio de un juego precedente), por aversión a perder (los agentes eligen sólo los equilibrios que exhiben resultados seguros $y$ positivos), o entonces por las ventajas que comporta ser el primero a jugar (el primero que toma la decisión en los juegos secuenciales). Asimismo, indica el Camerer, la selección del equilibrio no solamente es el resultado de las ganancias que se puedan obtener con él, sino también del riesgo implícito en la decisión, de manera que un equilibrio puede ser dominante por la ganancia o dominante por el riesgo. El primero hace posible obtener una ganancia más elevada, el otro genera una ganancia menor pero positiva $y$ segura $^{16}$.

Van Huyck et al. (1990), por su parte, sugieren que las decisiones de los agentes se fundan sobre dos principios: el principio de selección deductiva y el de selección inductiva. Según el primero, los jugadores eligen el equilibrio basándose en la descripción del juego solamente, es decir la decisión es independiente de la historia de las

\footnotetext{
"Una estrategia es dominada si al menos uno de los agentes la descarta porque, teniendo en cuenta la elección del otro agente, ella le brinda ganancias inferiores que las 'Una estrategia es dominada si al menos uno de los agentes la descarta porque, teniendo en cuenta la elección del otro agente, ella le bia 3 , su respuesta racional será jugar la estrategia 2 ( $1000>600$ ). otras estrategias. Por ejemplo, en el caso de la figura 2.1 , si el agente l piensa que el otro elegira la estrategia 3 , su respuesta ejemplo.
} 
interacciones. El otro principio, de selección inductiva, permite tomar las decisiones a partir de hechos anteriores, en este caso la historia de las interacciones juega un papel determinante.

Es interesante recalcar finalmente que muchos autores estudian la selección de los equilibrios a través de experimentos, es el caso de Cooper et al. (1990). Para verificar algunas hipótesis relativas a cómo los agentes escogen los equilibrios, los autores utilizan juegos "a un golpe ${ }^{\prime 17}$ con múltiples equilibrios (como aquél de la figura 2.1). Dos resultados interesantes se desprenden del experimento. Por un lado, el experimento muestra que los agentes no siempre otorgan más importancia a los equilibrios que generan ganancias más elevadas; por otro lado, se observa que las estrategias dominadas no son desdeñables ya que ellas influyen también en toma de decisiones y por ende en la selección del equilibrio.

A diferencia de Cooper et al., Van Huyck et al. (1990) hacen un experimento utilizando juegos de coordinación repetidos. Ellos observan que la repetición de un juego un número limitado de veces, permite que los jugadores conozcan el comportamiento de los otros y, en consecuencia, que disminuyan su incertidumbre estratégica. Sin embargo, a pesar de la información adicional obtenida a través de la repetición del juego, el estudio demuestra que las fallas de coordinación persisten. En efecto, se observa que, en algunos casos, el equilibrio dominante por la ganancia no es seleccionado ni en el primer juego ni en la repetición del mismo. La selección del equilibrio ineficaz se debe, explican los autores, al riesgo implícito en la estrategia: algunos jugadores piensan que es muy arriesgado seleccionar la estrategia que produce la ganancia más elevada, motivo por el cual ellos optan siempre por la estrategia que exhibe un resultado inferior pero seguro. Finalmente, después de efectuar algunas modificaciones en los parámetros, Van Huyck evidencian que la probabilidad de coordinarse aumenta a medida que el número de participantes disminuye.

En resumen, a partir del examen de la literatura constatamos que los juegos de coordinación sirven para analizar las interacciones estratégicas en toda clase de modelos económicos. En general, ellos son utilizados en los modelos que consideran la presencia de riesgo moral, en aquellos que estudian la incertidumbre estratégica, así como en los que tratan las fallas de coordinación a nivel macroeconómico. Este tipo de juegos ha servido de marco de análisis para experimentos (Cooper et al., 1990; Harsanyi et al., 1998; Van Huyck et al., 1990), pero también ha sido aplicado a situaciones cotidianas, para explicar distintos aspectos de las interacciones sociales (Schelling, 1986). Nosotros los utilizaremos para analizar las interacciones entre los productores de la industria del pisco.

\section{LA APLICACIÓN DE LOS JUEGOS DE COORDINACIÓN A LA INDUSTRIA DEL PISCO}

En base al análisis cualitativo de la información empírica, realizado en la primera sección del artículo, y de las nociones teóricas presentadas en la sección 2, procedemos a formalizar el caso del pisco a través de un modelo. En otras palabras, presentamos la misma problemática, pero ahora en el lenguaje de la teoría económica. Cabe recordar que el modelo es una abstracción de un hecho concreto, en este caso de la interacción entre los agentes que desean posicionar el producto internacionalmente. Para que esta abstracción sea coherente con la teoría, es necesario plantear algunos supuestos, nosotros lo hacemos en el apartado 3.1.1 de esta sección.

\subsection{El modelo}

Consideremos el caso de dos productores de pisco que evalúan la posibilidad de invertir en el posicionamiento del producto en un mercado extranjero. Suponemos que estos inversionistas potenciales poseen la capacidad de exportar, es decir, ellos no tienen ninguna restricción para aumentar su producción y, además, su producto respeta los estándares internacionales de calidad. 
Presumimos también que el mercado no está saturado.

Estos dos productores hacen parte de un juego a información completa y tienen a su disposición tres estrategias: no invertir, invertir un monto con el fin de realizar ventas esporádicas en el corto plazo o invertir un monto que les permita abrir un mercado y mantener una demanda en el mediano y largo plazo. Debemos subrayar que los agentes seleccionan sus estrategias de manera independiente y simultánea.

Los resultados de la estrategia elegida por los dos productores son proporcionales a la inversión que ellos deciden realizar. En ese sentido, si un agente no invierte, el obtiene una ganancia nula; el riesgo asociado a esta decisión es también nulo. Por el contrario, si el agente invierte, él puede obtener ganancias positivas en función de la decisión del otro productor. El optimo social (situación en la que ningún agente puede obtener mejores resultados sin empeorar la situación de otro) es alcanzado solamente si los dos productores deciden invertir, al mismo tiempo, el monto más elevado.

Formalmente, supongamos el caso de dos empresas idénticas, $i=(1,2)$, que desean comercializar su producto internacionalmente. Concretamente, cada agente $i$ estudia la posibilidad de invertir en marketing y en promoción con el fin de abrir un mercado extranjero y posicionar su producto. Como muestra la matriz de rendimientos del juego (figura 3.1), el espacio de estrategias del productor $i$ contienen tres estrategias, $s_{i}=(\mathrm{N}, \mathrm{I})$, donde $s_{i} S_{i}, \mathrm{y}$ donde $\mathrm{N}$, I son tres niveles diferentes de inversión. En otras palabras, los productores pueden decidir no invertir $(\mathrm{N})$, invertir un monto que permita realizar una venta esporádica (I) en el corto plazo, ó invertir una cantidad (I) con la que se pueda posicionar el producto, en función de la decisión de la otra empresa.

Figura 3.1 - Juego de coordinación de la industria del pisco

Agente 2

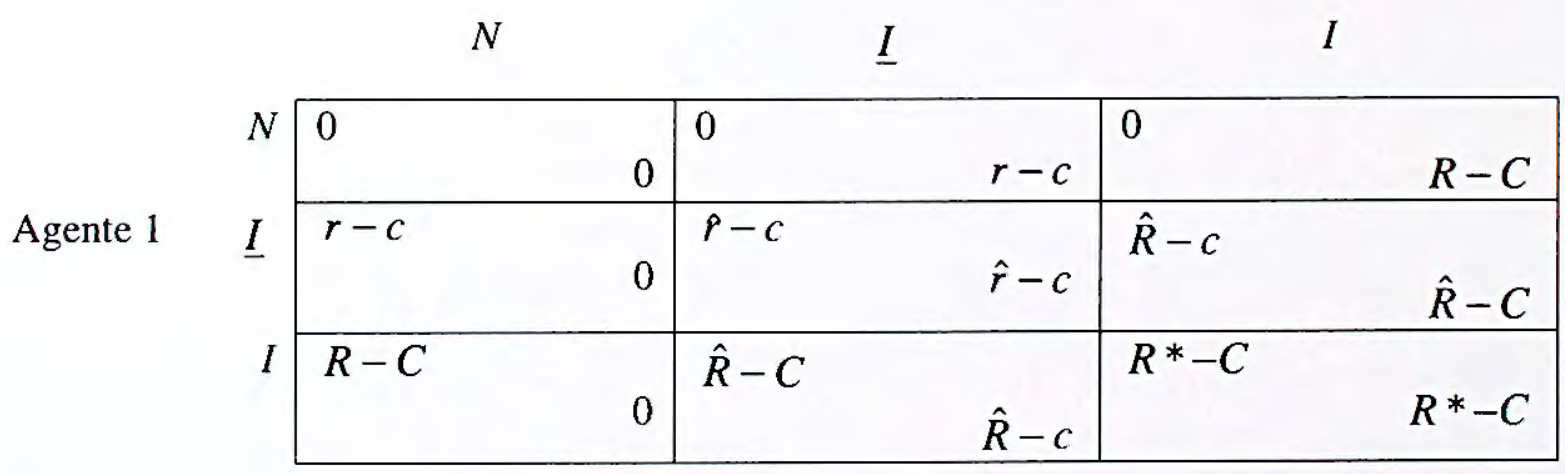


En esta matriz, los ingresos generados por la inversión son $r$ y $R$, los costos de inversión en promoción y marketing $c$ y $C$. Adicionalmente, el juego exhibe externalidades positivas ${ }^{18}$, es por ello que $r \quad P$ yque $R \quad R \quad R^{*}$. Es decir, como se trata de un producto que cuenta con denominación de origen, el agente que realiza una inversión menor en marketing y promoción internacional obtiene beneficios adicionales gracias al productor que realizó un esfuerzo de inversión mayor.

\subsubsection{Algunas hipótesis}

Con el propósito de estructurar el juego formulamos algunas hipótesis, relacionadas con la inversión, la producción, el mercado y las estrategias. En tal sentido, suponemos que no existen restricciones a la producción, es decir, que ella puede incrementarse por decisión del productor. Además, consideramos que existe una demanda potencial (el mercado no está saturado) y que el costo de inversión disminuye con el tiempo.

Con relación a las estrategias, presumimos que la estrategia $(I, I)$ constituye el óptimo social, es decir $0 \quad\left(\begin{array}{llll}2 \hat{R} & C & c\end{array}\right) \quad 2\left(R^{*} C\right)$. Como se indica en la sección precedente, la industria del pisco está caracterizada por la presencia de un gran número de pequeños y medianos productores que no tienen la capacidad de solventar, de forma individual, los costos relacionados a la apertura de nuevos mercados internacionales. Es por ello que el optimo social es alcanzado solamente si las empresas invierten el monto / al mismo tiempo.

Asimismo, teniendo en cuenta la presencia de externalidades y la alta probabilidad de que el fenómeno de "disfrute libre" (free riding) se produzca, suponemos que las ganancias más elevadas del juego son obtenidas por uno de los agentes cuando él invierte mientras que el otro selecciona el monto de inversión $I$. Observamos entonces que $\left.\begin{array}{llllll}0 & \left(\begin{array}{llll}R & C\end{array}\right) & \left(R^{*} C\right. & C\end{array}\right)\left(\begin{array}{ll}R & c\end{array}\right)$.

Conjeturamos también que los productores asumen pérdidas cuando ellos invierten al mismo tiempo. En este caso el monto invertido no es suficiente para realizar ningún tipo de ventas, incluso aquellas que son esporádicas. Finalmente, la selección de $(N, N),(N, I)$ y viceversa generan

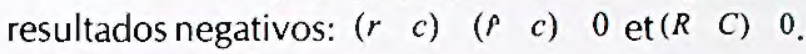

3.1.2 Los resultados del juego

Como evidencia la figura 3.1, si ninguno de los productores realiza la inversión, el ingreso neto de los dos agentes es nulo. Siendo el costo igual a cero, el riesgo asociado a esta acción es también nulo. En este caso, el mercado no es abierto y el producto no es posicionado. En cambio, cuando las dos empresas realizan una inversión l, cada una de ellas asume un costo $C$ y obtiene un ingreso $R^{*}$, donde $R^{*}>$ C. La selección de esta estrategia de manera simultánea constituye el óptimo social, siendo / la solución de coordinación.

Cuando los agentes realizan inversiones asimétricas, aquél que invierte el monto inferior (o que no invierte nada) obtendrá siempre ganancias positivas (o nulas); el otro estará en una situación más desventajosa. En el caso específico de los agentes 1 y 2 :

- Si el productor 1 selecciona el nivel de inversión I al tiempo que el otro no invierte nada, el agente 1 deberá asumir las pérdidas más importantes del juego.

- Si el agente 1 decide invertir I mientras que 2 elige el monto de inversión inferior, el primero recibirá una ganancia positiva pero pequeña; el segundo obtendrá la ganancia más elevada del juego.

- Si 1 elige, cuando 2 no invierte nada, el productor 1 tendrá una resultado negativo, $(\mathrm{r}-\mathrm{C})$ $<0$; el agente 2 exhibirá una ganancia nula.

Con respecto a los equilibrios, el juego presenta tres equilibrios de Nash en estrategias puras. Los dos primeros, (I,I) y(I,I), son equilibrios asimétricos que exhiben resultados positivos; el otro, $(N, N)$, es un equilibrio simétrico con el cual se obtienen ganancias nulas. Dirigiendo la atención hacia los equilibrios asimétricos, observamos que es la mejor respuesta del agente 1 a la decisión de 2 de 
elegir l; esta decisión permite que 1 obtenga las ganancias más altas del juego invirtiendo un monto mínimo. Utilizando una argumentación similar, vemos por qué (I,I) es también un equilibrio. En este caso, los dos productores podrán realizar una venta puntual, pero el producto no será posicionado en el mercado (la empresa que invierte aprovecha la oportunidad de ser un free rider con el fin de maximizar sus ganancias). Es importante anotar que el optimo social, (I,I), no es seleccionado porque con él uno de los agentes obtiene una ganancia menor a aquella que puede adquirirse con el equilibrio asimétrico.

Ahora bien, habiendo determinado la existencia de tres equilibrios, procederemos a analizar la selección de uno entre ellos. Dos elementos deben ser considerados para tal fin. Por un lado, tiendo en cuenta que los agentes son racionales (desde el punto de vista económico) y que por ende ellos intentan maximizar sus ganancias, la selección del equilibrio (I,I ) ó (I,I ) sería justificada. Sin embargo, si una empresa decide realizar el esfuerzo de inversión $/$ es porque ella desea posicionar su producto internacionalmente, ¿por qué, entonces, ella correría el riesgo de efectuar una inversión que no le brinde ganancias sostenibles en el mediano y largo plazo? Por otro lado, si cada empresa desea obtener la ganancia más alta posible aprovechando la inversión realizada por la otra, ellas se arriesgan a afrontar pérdidas: el resultado de selección simultánea de la estrategia es negativo. No invertir, $(N, N)$, se convierte de esta manera en el único equilibrio del juego. Se trata de un equilibrio dominante por el riesgo (Harsanyi et al., 1998; Cooper, 1999). Dicho en otros términos, el riesgo que comporta esta estrategia induce a los agentes a no realizar el esfuerzo de inversión para posicionar el producto.

Puesto que los agentes pueden obtener mejores resultados coordinando sus acciones, la selección del equilibrio dominante por el riesgo constituye una falla de coordinación. Esta deficiencia, que no permite incrementar la comercialización del pisco en los mercados internacionales, es debida esencialmente a la ausencia de confianza de cada agente frente a la decisión del otro.
De esta manera vemos cómo la teoría de juegos permite formalizar la toma de decisiones y la interacción de los productores que participan en la industria del pisco. Empleando el equilibrio de Nash como concepto de solución, hemos podido explicar las razones por las cuales los agentes no incrementan sus esfuerzos de inversión con el fin de posicionar el producto en los mercados internacionales. Teniendo en cuenta que el óptimo social es la estrategia más interesante del juego y que él no es seleccionado por el riesgo que implica, exploramos, en el capitulo siguiente, algunas medidas de política publica podrían incitar a los agentes a incrementar sus esfuerzos de inversión y a desarrollar estrategias conjuntas.

\section{4.¿Cómo solucionar las fallas de coordinación?}

Algunos instrumentos de política pública en esta sección analizamos los resultados de la aplicación de tres instrumentos de política pública. En primer lugar, estudiamos los efectos de una ayuda a la exportación (créditos fiscales o subvenciones, por ejemplo) otorgada a todos los agentes que deciden invertir para exportar su producto. Luego, se considera la puesta en marcha de una política de ventajas fiscales "discriminatorias" concedidas a las empresas que invierten el monto que permite posicionar internacionalmente el pisco. Finalmente, consideramos los resultados de una política basada en incentivos concedidos a empresas que invierten en la apertura de nuevos mercados a través de organizaciones colectivas (cooperativas o consorcios de exportación, por ejemplo).

\subsection{Política de ayuda a la exportación}

Supongamos que el gobierno concede incentivos fiscales, a todos los agentes que exportan el producto (a través de subvenciones, de créditos fiscales o de inversiones directas en promoción, por ejemplo), con el fin de aumentar los ingresos o de disminuir los costos. En consecuencia, los productores que deciden invertir tanto como I obtienen un incremento en sus ingresos. Los resultados de esta política se ilustran en la siguiente matriz de rendimientos: 
Figura 4.1 - Ayuda a la exportación

Agente 2

\begin{tabular}{|c|c|c|c|c|c|}
\hline & & $N$ & & $\underline{I}$ & $I$ \\
\hline \multirow{3}{*}{ Agente 1} & $N$ & 0 & 0 & $r+\alpha-c$ & $R+\alpha-C$ \\
\hline & $\underline{I}$ & $r+\alpha-c$ & 0 & $\hat{r}+\alpha-c$ & $\hat{R}+\alpha-c$ \\
\hline & $I$ & $R+\alpha-C$ & 0 & $\begin{array}{ll}\hat{R}+\alpha-C & \\
& \hat{R}+\alpha-c\end{array}$ & $\begin{array}{l}R^{*}+\alpha-C \\
R^{*}+\alpha-C\end{array}$ \\
\hline
\end{tabular}

En parágrafos precedentes, supusimos que cuando los dos agentes seleccionan simultáneamente la acción, ellos obtienen un resultado negativo. Una política de ayuda a la exportación puede hacer cambiar este resultado; a través de este incentivo es posible que la estrategia genere ganancias. Sin embargo, teniendo en cuenta que cada jugador obtiene la ganancia más elevada del juego seleccionando (como respuesta a la decisión del otro de jugar $l)^{19}$, el resultado es el mismo que aquél del juego original. El juego presenta entonces los mismos tres equilibrios en estrategias puras: $(N, N)$, $(I)$ y $(I, I)$. Esta constatación nos permite formular una primera proposición.

\section{Proposición 1}

La aplicación de una política de ayuda a la exportación que no discrimina las empresas en razón del monto invertido en la comercialización internacional del producto, no constituye un incentivo para hacer aumentar el esfuerzo de inversión. Esta política no permite resolver el problema de coordinación.

Es interesante notar que esta política se aplica actualmente en Perú con el fin de incrementar el nivel de exportaciones. A través de la Oficina de Regímenes Aduaneros, los exportadores peruanos tienen a su disposición dos tipos de incentivos: la devolución del impuesto general a las ventas y el reintegro de los aranceles correspondientes a la compra de insumos importados. Asimismo, en el caso de la industria del pisco, el gobierno invierte indirectamente en promoción. Analizando esta medida constatamos que ella no ha conseguido incrementar el esfuerzo de inversión de los agentes con el objeto de posicionar el producto en mercados internacionales. Por el contrario, este incentivo ha hecho aumentar temporalmente los ingresos de los agentes que, trabajando de manera individual, realizan algunas ventas puntuales.

\subsection{Ventajas fiscales discriminatorias}

A continuación exploramos los efectos de una medida que permite obtener créditos fiscales a las empresas que invierten en posicionar el producto internacionalmente. Es oportuno recordar que los productores que hacen parte de la industria del pisco no tienen la capacidad económica para invertir en marketing y promoción internacional de manera individual, es por ello que el posicionamiento internacional del producto depende del esfuerzo colectivo. En el contexto de nuestro modelo, esta ventaja fiscal, representada por sería otorgada a los agentes que seleccionen el nivel de inversión I. La matriz de rendimientos de la figura 4.2 muestra los efectos de esta política sobre las ganancias y los equilibrios.

\footnotetext{
"Es decir que $0<(P+\alpha-c)<(R+\alpha-C)<\left(R^{*}+\alpha-C\right)<(R+\alpha-c)$
} 
Figura 4.2 - Ventajas fiscales de acuerdo a monto invertido

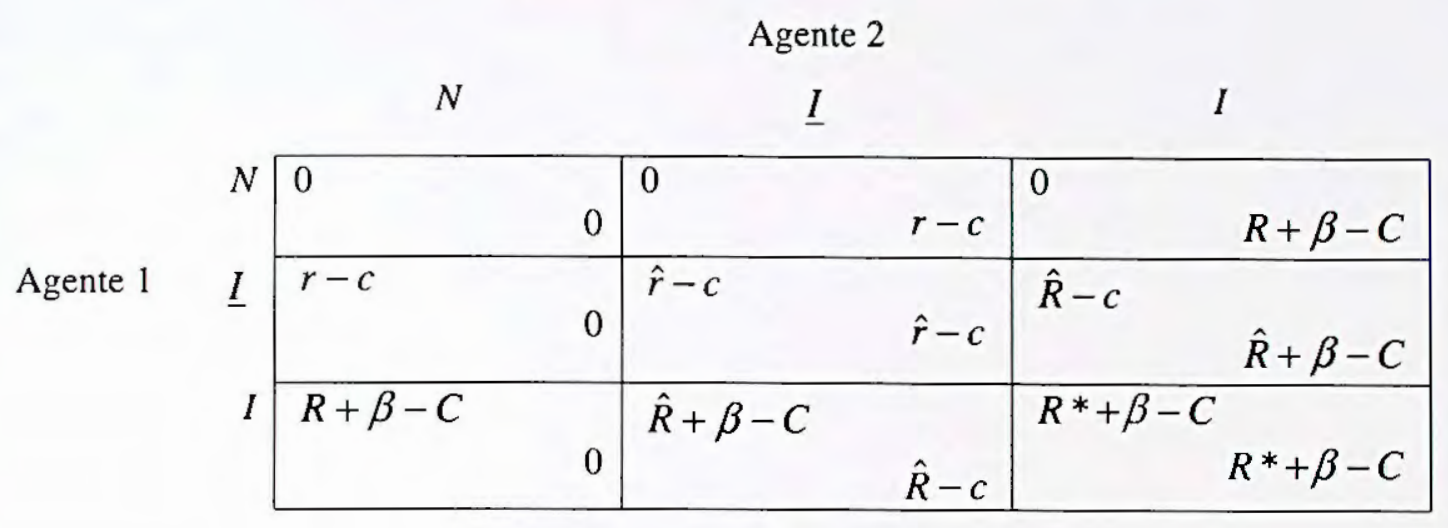

Supongamos que, por un lado, el resultado de la estrategia $(I, N)$ es negativo, es decir ( $\mathrm{R}+\mathrm{B}$ C) $<0$. Teniendo en cuenta que( $\left.\begin{array}{lll}R & C\end{array}\right)\left(\begin{array}{ll}R^{*} & C\end{array}\right)$, observamos que el juego presenta dos equilibrios de Nash en estrategias puras: $(N, N)$ y $(I, I)$. Ante este resultado, la selección de la estrategia / será la posibilidad más ventajosa para ambos agentes. El crédito fiscal se muestra así como una solución al problema de coordinación en la industria del pisco: gracias a este incentivo, las ganancias obtenidas con el equilibrio $(I, I)$ son mayores a aquellas obtenidas con cualquier otra estrategia.

Sin embargo, la pertinencia de esta política puede ser fácilmente cuestionada en el contexto de la industria que estudiamos. Es posible, por ejemplo, considerar la presencia de empresas que, con un comportamiento oportunista, busquen beneficios a corto plazo; ante la posibilidad de aumentar sus ganancias, ellas seguirían seleccionando. Además, una política de este tipo puede estimular la colusión entre las empresas más grandes dejando en desventaja a los consumidores, particularmente a los del mercado nacional. Finalmente, si bien esta medida puede hacer aumentar la comercialización del pisco, ella no garantiza que los agentes se coordinen con el fin de abrir nuevos mercados internacionales; ella beneficiaría aún más a los productores que ya realizan la exportación del producto.

\subsection{Subvenciones colectivas}

Las subvenciones otorgadas a las empresas que desean realizar operaciones de marketing internacional a través de acciones colectivas pueden constituir una solución alternativa a los problemas de coordinación en contextos donde el capital social es inexistente o débil. Por un lado, esta ayuda pública permite que los agentes superen ciertas restricciones financieras. Por otro, la subvención incentiva a las sociedades a interrelacionarse estableciendo redes. Es decir, una subvención colectiva puede servir para la construcción de capital social.

La experiencia española es un buen ejemplo de la aplicación de una política de este tipo. Efectivamente, con el fin de incentivar a las empresas para que posicionen sus productos y servicios en mercados extranjeros, el gobierno español, a través del Instituto Español de Comercio Exterior (ICEX), otorga beneficios económicos a consorcios de exportación, los cuales agrupan a pequeñas y medianas empresas. En los casos en los cuales la demanda de subvención es aceptada, el consorcio, constituido por un mínimo de cuatro empresas, recibe hasta 900,000 euros que deben ser utilizados para promover, comercializar y posicionar un producto. La renovación anual de la subvención está condicionada a los resultados obtenidos por el consorcio ${ }^{20}$. 
Este tipo de política, acompañado de la participación activa de los empresarios, ha permitido aumentar la presencia de productos españoles en ciertos mercados internacionales. En el caso del vino de Rioja, por ejemplo, se observa que la ayuda publica ha contribuido a posicionar el producto en el mercado europeo (Reino Unido, Alemania y Suiza) y Norte americano ${ }^{21}$.

Teniendo en cuenta que el mercado del pisco se caracteriza por la presencia de un gran número de pequeñas y medianas empresas que, de manera individual, no tienen la capacidad de inversión para posicionar el producto en el mercado internacional, una ayuda publica incentivando la formación de consorcios podría ser eficaz.

En el contexto de nuestro modelo, suponemos la presencia de dos agentes que desean posicionar su producto en un mercado extranjero. El espacio de estrategias así como las ganancias son similares a las especificados en el juego original (figura 3.1); la única diferencia reside en los resultados de la estrategia (I,I). Efectivamente, las empresas que deciden invertir $\mathrm{I}$ al mismo tiempo, reciben una subvención; ésta incrementa sus ingresos. La figura 4.3 ilustra los resultados de esta política.

Figura 4.3 - Subvenciones a través de consorcios de exportación

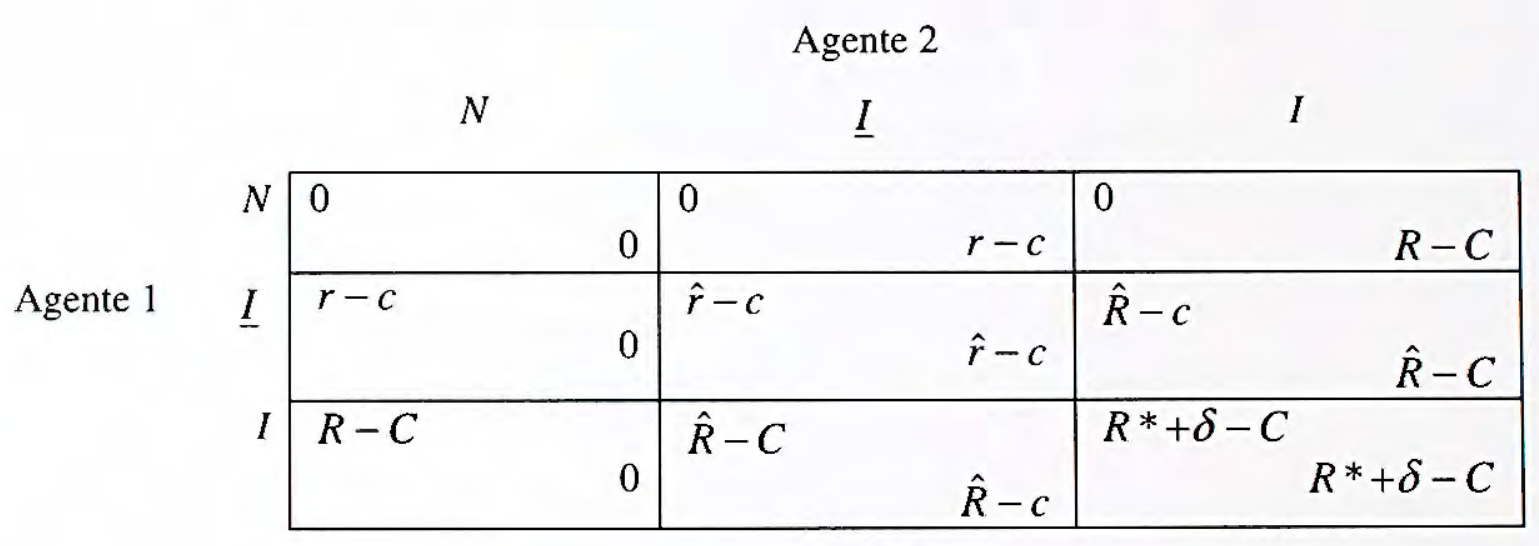

Presumiendo que los resultados de las estrategias $(\mathrm{I}, \mathrm{N}),(\mathrm{I}, \mathrm{N})$ y $(\mathrm{I}, \mathrm{I})$ son negativos, observamos que, gracias a la subvención colectiva, las ganancias obtenidas con la estrategia (I,I) son las más importantes del juego; esto significa que $\left(\begin{array}{llll}R & C\end{array}\right)\left(\begin{array}{llllll}R & C\end{array}\right)\left(\begin{array}{lll}R & C\end{array}\right)\left(\begin{array}{ll}R^{*} & C\end{array}\right)$.

El juego exhibe dos equilibrios en estrategias puras $(N, N)$ y $(I, I)$. Con el primero se obtiene una ganancia nula, el otro permite obtener las máximas ganancias del juego. Teniendo en cuenta que los agentes tienen la intención de comercializar el producto internacionalmente, el equilibrio dominante por ganancia, $(I, I)$, constituye el solo equilibrio. Este instrumento constituye entonces un medio eficaz para aumentar las ventas internacionales y posicionar el producto.

\section{Proposición 2}

En presencia de un gran numero de pequeños $y$ mediamos productores, una política que fomenta la acción colectiva de los agentes, permite resolver problemas de coordinación. Esta medida hace aumentar el esfuerzo de inversión de los agentes e incita la selección del óptimo social.

\footnotetext{
${ }^{21}$ Los sitios Internet siguientes ofrecen informaciones relativas a la evolución de las estrategias aplicadas a partir del año 2001 con el fin de posicionar el vino de Rioja: http://www.consumer.es/web/es/alimentacion/2001/08/27/44889.php, http://www.noticiasderioja.com/2005/0505141.html. 
Para explicar este resultado, supongamos que un agente seleccione la estrategia, la mejor respuesta del otro será elegir I. El par de acciones, (I, I), exhibe ganancias positivas para las dos empresas; sin embargo, estas ganancias son menores a las obtenidas con (I, I). La selección de la estrategia (I,I) revela que uno de los agentes supone que el otro no intenta maximizar sus ganancias, suposición que contradice el principio básico de un equilibrio de Nash. Además, en el nivel de inversión (I, I) las ventas no son sostenibles en el largo plazo: si bien admite resultados positivos, este nivel de inversión no permite posicionar el producto. Finalmente, si los dos agentes deciden seleccionar (I,I), ellos obtienen perdidas. Ninguna empresa tendrá, entonces, interés en desviar del equilibrio (I, I).

Con respecto al equilibrio $(\mathrm{N}, \mathrm{N})$, él es seleccionado en el juego original (figura 3.1 ) en respuesta al riesgo que los equilibrios asimétricos comportan. Considerando que en el juego que incluye las subvenciones colectivas los agentes racionales nunca seleccionarán, el riesgo de obtener un resultado negativo es eliminado.

Es oportuno señalar finalmente que la aplicación de esta medida comporta ventajas adicionales. Por un lado, ella permite disminuir la probabilidad de riesgo moral gracias al mecanismo de vigilancia que el grupo ejerce sobre cada uno los miembros del consorcio. Así como en los programas de crédito colectivo, en los cuales un grupo de prestatarios se hace responsable de los prestamos de cada uno de sus pares (Stiglitz, 1990), los miembros del consorcio de exportación vigilan la performance de sus miembros con el fin de aumentar sus propias ganancias. Por otro lado, ésta es una manera de iniciar una historia de interacciones entre los agentes que participan en la industria. Así, la subvención a través de consorcios de exportación puede hacer aumentar la información entre los agentes e incitar la construcción de capital social.

\section{CONCLUSIÓN}

En este artículo hemos presentado un análisis económico de la industria del pisco, más precisamente del posicionamiento internacional del producto. El estudio nos ha permitido constatar que se trata de una industria que cuenta con amplias posibilidades de crecimiento pero en la cual numerosos son los problemas de coordinación.

Los juegos de coordinación nos han servido para formalizar el caso y para estudiar los efectos de tres instrumentos de política pública. El primero, aplicado actualmente en el contexto peruano, es ineficaz si se trata de fomentar los esfuerzos de inversión. La segunda política, un incentivo fiscal otorgado a las empresas que invierten un monto determinado, podría incitar a que las empresas incrementen los niveles de inversión orientados a la comercializaron internacional del producto. Sin embargo, esta medida no estimula la formación de redes; ella no garantiza que la interrelación entre los agentes sea sostenible y, por el contrario, puede favorecer la concentración de la oferta. Finalmente, examinamos los efectos de un instrumento por medio del cual se otorga subvenciones a los productores que desarrollen estrategias colectivas orientadas a posicionar el producto en un mercado internacional. Esta política, inspirada en la experiencia española, permite superar las fallas de coordinación y parece ser un incentivo eficaz para construir capital social.

Cabe resaltar finalmente que este estudio hace parte de una investigación más amplia sobre el capital social, el empresariado y el desarrollo. En la continuación del mismo, afinaremos la formalización de la noción de capital social. Para tal fin, emplearemos algunos conceptos adicionales como el de los equilibrios correlacionados sugerido por Aumann (1987).

\section{BIBLIOGRAFÍA}

1. Aumann, R., Correlated Equilibrium as an Expression of Bayesian Rationality. Econometrica, 1987.55(1): p. 1-18.

2. Bourdieu, P., "The forms of capital", in Handbook of theory and research for the sociology of education, J. Richardson, Editor. 1996, Greenwood Press, Inc.: Connecticut. p. $241-258$.

3. Bowles, S. \& H. Gintis, The moral economy of community: Structured Populations and the 
evolution of prosocial norms. Evolution \& Human Behaviour, 1998. 19(1): p. 3-25.

4. Bowles, S. \& H. Gintis, Social Capital and Community Governance. 2000: Massachusetts.

5. Camerer, C., Behavioral Game Theory. Experiments in Strategic Interaction. 2003, New York: Princeton University Press.

6. Coleman, J., Foundations of social theory. 1990, Cambridge: The Belknap Press of Harvard University Press.

7.Cooper, R., Coordination games. Complementarities and Macroeconomics. 1999, Cambridge: Cambridge University Press

8. Cooper, R., D. DeJong, F. Forsythe \& T. Ross, Selection criteria in coordination games: some experimental results. The American Economic Review, 1990.80(1): p. 218-233.

9. Dasgupta, P., Social Capital and Economic Performance: Analytics. 2002: Cambridge.

10.Del Busto, J.A., M. Zanutelli \& D. Wilson, eds. Crónicas y relaciones que se refieren al origen y virtudes del pisco bebida tradicional y patrimonio del Perú 1990, Banco Latino: Lima.

11.Dias Blue, A., The complete book of spirits. Vol. 1. 2004, New York: Harper Collins Books.

12. Gaucher, S., L.G. Soler \& H. Tanguy, Incitation à la qualité dans la relation vignoble - négoce. Cahiers d'Économie et Sociologie Rurales, 2002(62): p. 8-37.

13. Gibbons, R., Game theory for applied economics, New Jersey: Princeton University Press, 1992.

14. Harsanyi, J. and R. Selten, A General Theory of Equilibrium Selection in Games. Cambridge: The MIT Press, 1988.

15. Healy, T. \& S. Côté, Du bien-être des nations. Le rôle du capital humain et social. Organisation de Coopération et de Développement Économiques (OCDE): Paris, 2001.

16.Lichine, A., Encyclopédie des vins et des alcools de tous les pays. Vol. 1. New York: Bouquins, 1998.
17. Maddala, G. \& E. Miller, Microeconomía ed. McGraw-Hill. 1991, Mexico: McGraw-Hill.

18.Portocarrero, A., Plan estratégico de la Asociación nacional de productores agropecuarios de la vid al pisco PERU PISCO, in Congreso Nacional del Pisco. 2006: Arequipa.

19. Putnam, R., Making Democracy Work. Civic Traditions in Modern Italy. 1993, New Jersey: Princeton University Press.

20.Rosadio, A. \& R. Falcon, Estudio de competitividad del subsector vitivinícola. s.f. entre 2000 y 2005 , Lima: TechnoServe.

21. Russell E., Remeciendo a la Industria del Pisco, Revista electrónica Business Chile, Octubre 2006, N²38, en http: // www . Businesschile . $\mathrm{cl} /$ portada. $P h p ? w=$ old $\& i d=136 \& l a n=e s$ $\& q=$ enviepormail

22. Schelling, T., Stratégie du conflit. Perspectives internationales. 1986, Paris: Presses Universitaires de France.

23. Soler, L.G. \& H. Tanguy, Contrats et négociation dans le secteur des vins de Champagne. Gérer et comprendre, 1998. 51: p. 74-86.

24. Stiglitz, J.E., Peer Monitoring and Credit Markets World Bank Economic Review, 1990. 4(3): p. 351-366.

25. Van Huyck, J., R. Battalio \& R. Beil, Tacit coordination games, strategic uncertainty, and coordination failure. The American Economic Review, 1990. 80(1): p. 234-248.

26. Vitisphere, Conjoncture mondiale et prospective du secteur vin et spiritueux 2005, Vitisphere.com Économie,en:http://www.vitisphere.com, consultado el 11 de abril de 2007.

27. Woolcock, M., Social capital and economic development: Toward a theoretical synthesis and policy framework. Theory and Society, 1998. 27(2): p. 151-208. 